MACEDO, L.S.O. et al. Desenvolvimento e avaliação sensorial de sorvete à base de leite de cabra com sabor de frutas tropicais. PUBVET, Londrina, V. 8, N. 21, Ed. 270, Art. 1803, Novembro, 2014.

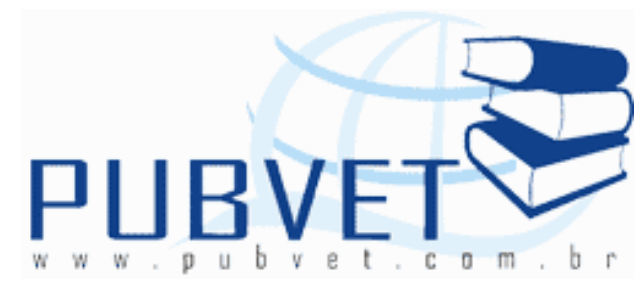

PUBVET, Publicações em Medicina Veterinária e Zootecnia.

\title{
Desenvolvimento e avaliação sensorial de sorvete à base de leite de cabra com sabor de frutas tropicais
}

\section{Lívia de Sousa Oliveira Macedoㅜ; Thaís Silva da Rocha ${ }^{1}$; Aline Raquel Pereira Ferreira $^{1}$; Jefferson Messias Borges ${ }^{1}$; Luan Ícaro Freitas Pinto ${ }^{1}$; Antônio de Sousa Júnior ${ }^{2}$; Lidiana de Siqueira Nunes Ramos ${ }^{3}$}

${ }^{1}$ Graduados em Tecnologia de Alimentos - Instituto Federal de Educação, Ciência e Tecnologia do Piauí (IFPI);

${ }^{2}$ Médico Veterinário, Mestre em Ciência Animal e Técnico em Laboratório do setor de Biotecnologia e Reprodução da Universidade Federal do Piauí (UFPI); 3 Médica Veterinária, Doutora em Ciência Animal e Professora do Curso de Tecnologia de Alimentos - IFPI.

\section{Resumo}

A produção de sorvete de frutas tropicais à base de leite de cabra agrega num só produto boas propriedades nutricionais e funcionais. Objetivou-se desenvolver, verificar a aceitação sensorial e intenção de compra de sorvetes com sabor de frutas tropicais à base de leite de cabra. A pesquisa foi segmentada em duas etapas. Na primeira etapa foram processados três tratamentos correspondentes a diferentes sabores de sorvetes (bacuri, cajá e maracujá) à base de leite de cabra. Na segunda etapa foram elaborados três sorvetes com diferentes concentrações do sabor mais bem aceito na primeira etapa. Após o processamento dos sorvetes as análises sensoriais ocorreram 
MACEDO, L.S.O. et al. Desenvolvimento e avaliação sensorial de sorvete à base de leite de cabra com sabor de frutas tropicais. PUBVET, Londrina, V. 8, N. 21, Ed. 270, Art. 1803, Novembro, 2014.

em dois momentos distintos. Na primeira etapa foi aplicado um teste de ordenção-preferência e os dados submetidos ao teste de Friedman e na segunda etapa as três formulações dos sorvetes do sabor mais bem aceito da primeira etapa, contendo diferentes concentrações do sabor de fruta tropical $(26 \% ; 30 \% ; 34 \%)$ à base de leite de cabra foram submetidos à avaliação sensorial através do teste de aceitação por escala hedônica e a teste de intenção de compra. Os dados obtidos na segunda etapa foram submetidos à análise de variância e as médias ao teste Student-Newman-Keuls a 5\% significância. O sabor de sorvete considerado preferido no teste de ordenaçãopreferência foi aquele elaborado com polpa de maracujá. O teste de aceitação mostrou que houve diferença estatística apenas para a cor e o teste de intenção de compra não mostrou diferença significativa entre as formulações.

Palavras-chave: Sorvete, análise sensorial, intenção de compra, produto regional.

\title{
Development and sensory evaluation of ice cream based on goat milk flavored with tropical fruits
}

\begin{abstract}
The production of tropical fruit ice cream from milk goat in one product combines good nutritional and functional properties. The objective is to develop, verify the sensory acceptance and purchase intent of ice cream with tropical fruit flavor based on goat's milk. The research was divided in two steps. In the first stage were processed three treatments of different flavors of ice cream (bacuri, hog plum and passion fruit) based on goat's milk. In the second phase were prepared with three different concentrations of ice cream taste better accepted in the first step. After processing sensory analysis of ice cream occurred at two different times. In a first step was applied ordençãopreference test data submitted to the Friedman test and the second stage of the three formulations of ice cream flavor in good standing of the first phase, containing different concentrations of the flavor of tropical fruit $(26 \%, 30 \%$,
\end{abstract}


MACEDO, L.S.O. et al. Desenvolvimento e avaliação sensorial de sorvete à base de leite de cabra com sabor de frutas tropicais. PUBVET, Londrina, V. 8, N. 21, Ed. 270, Art. 1803, Novembro, 2014.

$34 \%$ ) based on goat milk were subjected to sensory evaluation by testing for acceptance by hedonic scale test and purchase intent. The data obtained in the second stage were subjected to analysis of variance and the means to test Student-Newman-Keuls at $5 \%$ significance level. The favorite flavor of ice cream found in test-ordering preference that was made with passion fruit pulp. Acceptance testing showed that there was statistical difference only for color and purchase intent test showed no significant difference between the formulations.

Keywords: Ice cream, sensory analysis, intention to purchase, regional products.

\section{INTRODUÇÃO}

A crescente busca pelo consumidor por alimentos ricos em compostos nutritivos e funcionais que proporcionem benefícios ao organismo impulsiona o mercado e estimula pesquisas para o desenvolvimento de novos produtos alimentícios. No Brasil, verifica-se uma tendência ascendente de estudos dos alimentos da flora e da fauna nativa do país gerando diversos produtos, a fim de atender as expectativas do mercado.

A valorização de matérias-primas regionais pode gerar desenvolvimento e sustentabilidade para as comunidades rurais. O segmento de exploração e elaboração de produtos que utilizem matérias-primas tradicionais de uma determinada região é de grande interesse para a sociedade, pois são atividades que correspondem ao tripé da sustentabilidade, uma vez que englobam o econômico, o social e o ambiental. O econômico porque além da geração de renda, há possibilidade de se obter bons lucros, o social por se tratar de uma forma de gerar ocupação e empregos no campo e ambiental pela necessidade da aprendizagem da conservação ou preservação da matéria básica utilizada no processo produtivo (KHAN et al., 2004).

O beneficiamento do leite de cabra no Piauí é um exemplo de investimento em matérias-primas locais que poderia ser projetado para o Estado, uma vez que há efetivo caprino para o desenvolvimento desta atividade. Segundo dados do 
MACEDO, L.S.O. et al. Desenvolvimento e avaliação sensorial de sorvete à base de leite de cabra com sabor de frutas tropicais. PUBVET, Londrina, V. 8, N. 21, Ed. 270, Art. 1803, Novembro, 2014.

Instituto Brasileiro de Geografia e Estatística (IBGE, 2009) o Piauí possui um rebanho de 1.389.384 de cabeças de caprinos, além disso, não há qualquer empresa que atue neste setor em solo piauiense.

A exploração comercial do leite de cabra além de gerar sustentabilidade para as comunidades rurais pode incrementar a renda da população devido à qualidade comprovada deste alimento. O leite de cabra destaca-se entre os alimentos de origem animal pela riqueza de sua composição nutricional, fornecendo calorias e aminoácidos essenciais em proporções iguais ou superiores aos recomendados pela Organização Mundial de Saúde (OMS), possui ainda altos teores de cálcio, selênio, fosfato e vitaminas $A$ e B (MAZOCHI, 2002). É reconhecido ainda por suas propriedades funcionais e terapêuticas. Segundo Ribeiro e Ribeiro (2001), o leite de cabra é recomendado para consumidores em todos os estágios de vida, por exemplo, para crianças, particularmente para aquelas intolerantes ao leite de vaca, para pessoas com doenças gastrointestinais, ou mesmo como suplemento para pessoas idosas e mal nutridas.

Embora possua excelentes características nutricionais, funcionais e terapêuticas o leite de cabra muitas vezes não é bem aceito por quem o consome por conter sabor e aroma residual, descrito por muitos consumidores como desagradável. Soluções tecnológicas, no entanto, podem ser adotadas para amenizar as características indesejáveis deste leite, a exemplo do desenvolvimento de derivados lácteos, como exemplo o sorvete, cuja formulação contenha compostos saborizantes e/ou aromáticos, polpas e/ou pedaços de frutas, açúcares, mel, etc (ALVES et al., 2009).

O sorvete é um produto bastante disseminado entre a população brasileira. Sua característica refrescante, saborosa e nutritiva atrai o público de todas as idades. De acordo com a Associação Brasileira das Indústrias de Sorvetes (ABIS) (ABIS, 2010), o mercado de sorvetes encontra-se em plena expansão no Brasil e, embora o consumo brasileiro seja considerado modesto frente ao de outros países a indústria sorveteira possui faturamentos milionários todos os anos no país. 
MACEDO, L.S.O. et al. Desenvolvimento e avaliação sensorial de sorvete à base de leite de cabra com sabor de frutas tropicais. PUBVET, Londrina, V. 8, N. 21, Ed. 270, Art. 1803, Novembro, 2014.

Investimentos na produção de sorvetes à base de leite de cabra com sabor de frutas tropicais pode ser uma excelente alternativa para cooperativas e pequenas indústrias rurais, pois em um só produto estarão agregadas boas propriedades nutricionais e funcionais tão procuradas pelo consumidor.

A utilização de frutas tropicais pode estabelecer um diferencial na composição dos sorvetes, especialmente devido ao sabor agradável atribuído a essas frutas e seus produtos. O bacuri, a cajá e o maracujá são exemplos de frutas que além do sabor bastante apreciado podem agregar valor econômico a sorvetes elaborados à base de leite de cabra, além de aumentar sua qualidade nutricional e aceitabilidade sensorial.

Desta forma, objetivou-se desenvolver, verificar a aceitação sensorial e intenção de compra de sorvetes com sabor de frutas tropicais à base de leite de cabra.

\section{MATERIAIS E MÉTODOS}

\section{Materiais}

O leite de cabra utilizado nesta pesquisa foi adquirido no setor de caprinocultura do Centro de Ciências Agrárias (CCA) da Universidade Federal do Piauí (UFPI). Após a ordenha, amostras do leite caprino in natura foram coletadas e encaminhadas, sob refrigeração, ao Núcleo de Estudos, Pesquisas e Processamento de Alimentos (NUEPPA) localizado na UFPI para as análises físico-químicas de controle de qualidade da matéria-prima. Os demais ingredientes utilizados no desenvolvimento dos sorvetes foram adquiridos no comércio local de Teresina, Piauí.

\section{Análises físico-químicas do leite de cabra}

As análises físico-químicas do leite de cabra foram realizadas em triplicata, por metodologia instrumental, utilizando-se o equipamento Ekomilk total ${ }^{\circledR}$ (KHAN et al., 2008) analisador de leite por ultrasom (Cap Lab). Foram analisados o teor de gordura $(\mathrm{g} / \mathrm{100 \textrm {g }})$, sólidos não gordurosos $(\mathrm{g} / 100 \mathrm{~g})$, densidade relativa $15 / 15^{\circ} \mathrm{C} \mathrm{g} / \mathrm{mL}$, proteína $(\mathrm{g} / 100 \mathrm{~g})$, índice crioscópico, lactose $(\mathrm{g} / 100 \mathrm{~g})$, condutividade e $\mathrm{pH}$. 
MACEDO, L.S.O. et al. Desenvolvimento e avaliação sensorial de sorvete à base de leite de cabra com sabor de frutas tropicais. PUBVET, Londrina, V. 8, N. 21, Ed. 270, Art. 1803, Novembro, 2014.

\section{Formulação dos sorvetes}

O leite de cabra utilizado nos processamentos das duas etapas da pesquisa foi levado em condições de refrigeração para o Laboratório de Alimentos do Instituto Federal de Educação, Ciência e Tecnologia do Piauí (IFPI), onde sofreu tratamento térmico a $90^{\circ} \mathrm{C}$ durante 20 minutos, em panela de inox e com auxílio de termômetro, e em seguida foi feito o resfriamento do mesmo a $8^{\circ} \mathrm{C}$.

A elaboração dos sorvetes foi segmentada em duas etapas. Na primeira etapa foram processados três tratamentos (sorvetes) correspondentes a diferentes sabores que foram definidos como: sorvetes de bacuri, de cajá e de maracujá à base de leite de cabra com iguais concentrações de todos os ingredientes listados na formulação da Tabela 1.

Tabela 1 - Ingredientes utilizados na elaboração dos três sorvetes à base de leite de cabra com sabor de frutas tropicais.

\begin{tabular}{lc}
\hline Ingredientes & Quantidades (\%) \\
\hline Açúcar cristal & 15 \\
Emulsificante & 2 \\
Gordura vegetal hidrogenada & 7 \\
Liga neutra & 1 \\
Leite de cabra em pó & 6 \\
Leite de cabra & 43 \\
Polpa de bacuri (Sorvete 1) & $(26)$ \\
Polpa de cajá (Sorvete 2) & $(26)$ \\
Polpa de maracujá (Sorvete 3) & $(26)$ \\
\hline Total (\%) & $\mathbf{1 0 0}$ \\
\hline
\end{tabular}

$\mathrm{Na}$ segunda etapa da pesquisa foram elaborados três tratamentos (sorvetes) no sabor maracujá que foi considerado o mais bem aceito na primeira etapa, estando à formulação dos mesmos listados na Tabela 2. 
MACEDO, L.S.O. et al. Desenvolvimento e avaliação sensorial de sorvete à base de leite de cabra com sabor de frutas tropicais. PUBVET, Londrina, V. 8, N. 21, Ed. 270, Art. 1803, Novembro, 2014.

\section{Tabela 2 - Formulações dos sorvetes à base de leite de cabra com diferentes concentrações de polpa de maracujá.}

\begin{tabular}{lccc}
\hline Ingredientes (\%) & \multicolumn{3}{c}{ Sorvetes } \\
\cline { 2 - 4 } & A & B & C \\
\hline Açúcar cristal & 15 & 18 & 21 \\
Emulsificante & 2 & 2 & 2 \\
Gord.veg. & 7 & 7 & 7 \\
hidrogenada & & & \\
Liga neutra & 1 & 1 & 1 \\
Leite de cabra em & 6 & 6 & 6 \\
pó & & & 29 \\
Leite de cabra & 43 & 36 & 34 \\
Polpa de maracujá & 26 & 30 & $\mathbf{1 0 0}$ \\
\hline Total (\%) & $\mathbf{1 0 0}$ & $\mathbf{1 0 0}$ & \\
\hline
\end{tabular}

Na Figura 1 está o fluxograma das etapas de desenvolvimento dos sorvetes à base de leite de cabra com sabor de frutas tropicais utilizado nas duas etapas da pesquisa. Para elaboração dos sorvetes todos os ingredientes presentes nas Tabelas 1 e 2 foram pesados, após a pesagem, homogeneizou-se em liquidificador o leite de cabra pasteurizado juntamente com a polpa de fruta, o açúcar, o leite de cabra em pó (Caprilat ${ }^{\circledR}$ ), a gordura vegetal hidrogenada líquida $\left(\right.$ Primor $^{\circledR}$ - BUNGE) e a liga neutra $\left(K_{E R R Y / S I B E R}{ }^{\circledR}\right)$. Depois de homogeneizada a mistura foi colocada em recipiente de plástico e levada ao congelador por um tempo médio de 4 horas. Em seguida, a mistura foi batida em batedeira juntamente com 0 emulsificante $\left(K_{E R R Y / S I B E R}{ }^{\circledR}\right)$ por 10 minutos, daí foi envasada e submetida novamente a congelamento. 
MACEDO, L.S.O. et al. Desenvolvimento e avaliação sensorial de sorvete à base de leite de cabra com sabor de frutas tropicais. PUBVET, Londrina, V. 8, N. 21, Ed. 270, Art. 1803, Novembro, 2014.

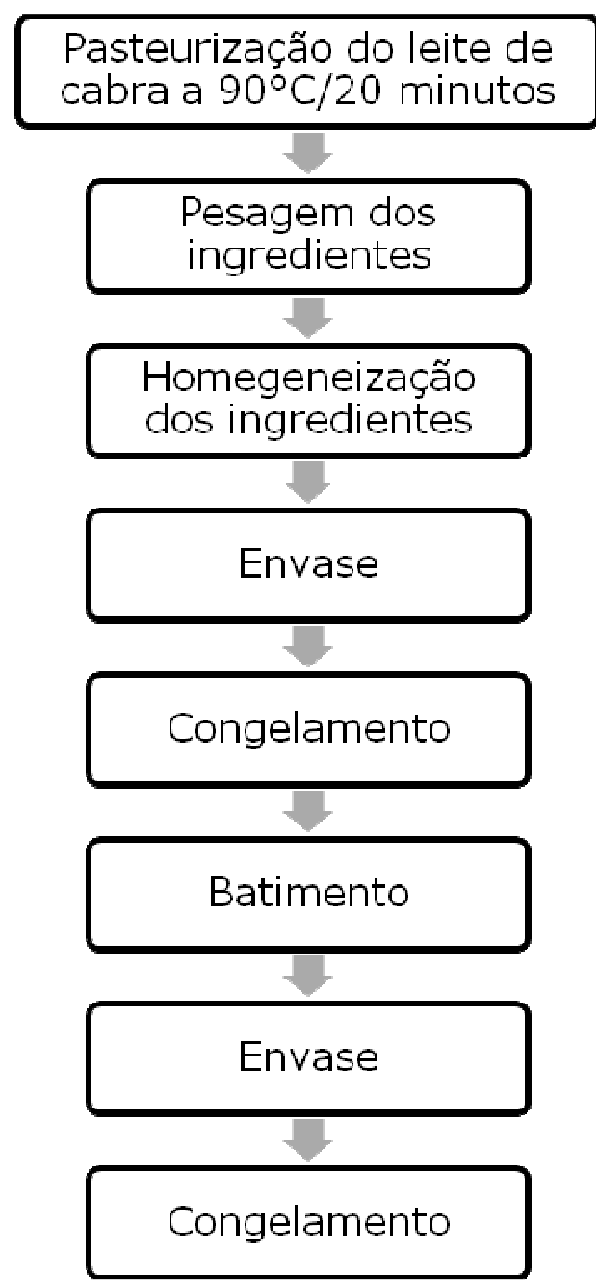

Figura 1 - Fluxograma de desenvolvimento do sorvete à base de leite de cabra com sabor de fruta tropical.

\section{Análise sensorial dos sorvetes}

As análises sensoriais foram realizadas no Laboratório de Alimentos do IFPI e ocorreram em dois momentos distintos sendo que em cada um deles foi utilizado um painel sensorial composto por 100 provadores não treinados entre alunos e funcionários da instituição. As amostras de sorvete foram apresentadas aos provadores em copos descartáveis codificados por três dígitos ao acaso. Na primeira etapa da análise sensorial foi aplicado um teste de ordenção-preferência, onde as amostras deveriam ser relacionadas na 
MACEDO, L.S.O. et al. Desenvolvimento e avaliação sensorial de sorvete à base de leite de cabra com sabor de frutas tropicais. PUBVET, Londrina, V. 8, N. 21, Ed. 270, Art. 1803, Novembro, 2014.

ordem de preferência do atributo sabor, conforme estabelecido pelo Instituto Adolfo Lutz - IAL (2008) e Dutcosky (1996), onde foram oferecidas aos provadores as três amostras de sorvetes à base de leite de cabra com sabor de frutas tropicais (bacuri, cajá e maracujá) (Tabela 1) e solicitou-se que os mesmos ordenassem o sabor de sorvete que considerassem como preferido sendo " 1 - menos preferido" e " 3 - mais preferido".

Na segunda etapa da pesquisa as três formulações dos sorvetes à base de leite de cabra com sabor de maracujá (Tabela 2), considerado mais bem aceito na primeira etapa foram submetidos à avaliação sensorial através do teste de aceitação por escala hedônica estruturada em nove pontos que contém termos situados entre "1 - desgostei muitíssimo; 2 - desgostei muito; 3 - desgostei moderadamente; 4 - desgostei ligeiramente; 5 - nem gostei, nem desgostei; 6 - gostei ligeiramente; 7 - gostei moderadamente; 8 - gostei muito; 9 - gostei muitíssimo". Além da avaliação da aceitação os sorvetes com diferentes concentrações de polpa de maracujá foram submetidos a teste de intenção de compra através de escala hedônica estruturada em cinco pontos onde "1 certamente compraria; 2 - provavelmente não compraria; 3 - tenho dúvidas se compraria; 4 - provavelmente compraria; 5 -certamente não compraria" (IAL, 2008).

Ao final das fichas utilizadas nos teste sensoriais (experimento 1 e 2 ) deixouse um espaço para que os provadores expressassem sugestões para melhorias futuras no processamento do produto.

\section{Análise estatística}

O delineamento experimental das duas etapas da análise sensorial foi realizado através de blocos casualizados. Os dados obtidos na primeira etapa do experimento, ou seja, do teste de ordenação-preferência dos sorvetes de bacuri, cajá e maracujá à base de leite de cabra, foram tabulados e submetidos à avaliação estatística através do Teste de Friedman utilizando-se a tabela de Newel e MacFarlane (IAL, 2008; DUTCOSKY, 1996) com nível de significância de $5 \%$. As médias foram comparadas por teste $\mathrm{T}$ de Student a $5 \%$. 
MACEDO, L.S.O. et al. Desenvolvimento e avaliação sensorial de sorvete à base de leite de cabra com sabor de frutas tropicais. PUBVET, Londrina, V. 8, N. 21, Ed. 270, Art. 1803, Novembro, 2014.

Os dados verificados na segunda etapa do experimento (avaliação sensorial e do teste de intenção de compra) foram submetidos à análise de variância, considerando três tratamentos (sorvetes à base de leite de cabra com 26\%; $30 \% ; 34 \%$ de polpa de maracujá) e as médias submetidas à comparação através do teste de SNK (Student-Newman-Keuls) com nível de 5\% significância em programa estatístico Statistical Analysis Sistem (SAS, 1997).

\section{RESULTADOS}

\section{Análises físico-químicas do leite de cabra}

Os resultados das análises físico-químicas do leite de cabra in natura utilizado na pesquisa, encontram-se na Tabela 3 abaixo juntamente com as especificações da Instrução Normativa No 37, que aprova o Regulamento Técnico de Identidade e Qualidade de Leite de Cabra (BRASIL, 2000).

\section{Tabela 3 - Resultados das análises físico-químicas do leite de cabra in natura do CCA - UFPI.}

\begin{tabular}{lcc}
\hline Características & Leite de Cabra & BRASIL (2000) \\
\hline Gordura $(\mathrm{g} / 100 \mathrm{~g})$ & $2,76 \pm 0,001$ & Teor original \\
Sólidos não-gordurosos $(\mathrm{g} / 100 \mathrm{~g})$ & $8,25 \pm 0,005$ & Mínimo 8,20 \\
Densidade $15 / 15^{\circ} \mathrm{C}$ & $1,0301 \pm 0,005$ & $1,0280-1,0340$ \\
Proteínas $(\mathrm{g} / 100 \mathrm{~g})$ & $2,83 \pm 0,005$ & Mínimo 2,8 \\
Ponto crioscópico $(\mathrm{OH})$ & $-0,554 \pm 0,005$ & $-0,550$ a $-0,585$ \\
Lactose $(\mathrm{g} / 100 \mathrm{~g})$ & $4,36 \pm 0,005$ & Mínimo 4,3 \\
pH & $6,40 \pm 0,08$ & - \\
\hline
\end{tabular}

*Valores das médias em triplicata e desvio padrão. 
MACEDO, L.S.O. et al. Desenvolvimento e avaliação sensorial de sorvete à base de leite de cabra com sabor de frutas tropicais. PUBVET, Londrina, V. 8, N. 21, Ed. 270, Art. 1803, Novembro, 2014.

\section{Análise sensorial}

Os resultados obtidos na primeira etapa da análise sensorial do sorvete à base de leite de cabra com sabor de frutas tropicais (bacuri, cajá e maracujá) (Tabela 4), mostraram que os sorvetes diferiram $(P<0,05)$ pelo teste de Friedman. O sorvete sabor de maracujá foi o mais preferido com o valor médio de 2,43 pontos e o menos preferido foi o sorvete sabor de cajá com o valor médio de 1,53 pontos.

Tabela 4 - Resultados do teste de ordenação-preferência dos sorvetes à base de leite de cabra com sabor de bacuri, cajá e maracujá.

\begin{tabular}{lc}
\hline Formulações & Médias* \\
\hline Bacuri & $2,04^{\mathrm{b}}$ \\
Cajá & $1,53^{\mathrm{c}}$ \\
Maracujá & $2,43^{\mathrm{a}}$
\end{tabular}

* Médias obtidas através do teste de Friedman. Médias seguidas por letras diferentes diferem $(P<0,05)$ pelo teste de $T$ de Student.

Os resultados do teste sensorial e de intenção de compra dos diferentes sorvetes à base de leite de cabra com sabor de maracujá estão presentes na Tabela 5.

$\mathrm{Na}$ verificação da aceitabilidade dos sorvetes de maracujá observou-se que o único atributo sensorial que diferiu estatisticamente $(p<0,05)$ foi a cor. 0 aroma dos sorvetes de maracujá foi correspondente a "gostei ligeiramente" (formulação B) e "gostei moderadamente" (formulações A e C). Quanto ao sabor e a textura dos sorvetes de maracujá estes foram definidos como "gostei moderadamente" pelo painel sensorial. Em relação aos atributos de aceitação global e intenção de compra os sorvetes de maracujá foram avaliados como "gostei moderadamente" e "tenho dúvidas se compraria", respectivamente. 
MACEDO, L.S.O. et al. Desenvolvimento e avaliação sensorial de sorvete à base de leite de cabra com sabor de frutas tropicais. PUBVET, Londrina, V. 8, N. 21, Ed. 270, Art. 1803, Novembro, 2014.

Tabela 5 - Resultados do teste sensorial e de intenção de compra dos diferentes sorvetes à base de leite de cabra com sabor de maracujá.

\begin{tabular}{ccccc} 
& \multicolumn{3}{c}{ Sorvetes** } & \\
\cline { 2 - 4 } Variáveis & $\mathrm{A}$ & $\mathrm{B}$ & $\mathrm{C}$ & CV (\%) \\
\cline { 2 - 4 } Cor & $7,22^{\mathrm{b}}$ & $7,02^{\mathrm{b}}$ & $7,57^{\mathrm{a}}$ & 21,14 \\
Aroma & 7,03 & 6,56 & 7,04 & 25,08 \\
Sabor & 6,49 & 6,12 & 6,48 & 33,90 \\
Textura & 6,69 & 6,53 & 6,87 & 28,73 \\
Aceitação & 6,84 & 6,44 & 6,79 & 28,09 \\
Global & & & & \\
Intenção de & 3,50 & 3,43 & 3,76 & 34,15
\end{tabular}

Compra

** Sorvete A: $26 \%$ de polpa de maracujá; sorvete B: $30 \%$ de polpa maracujá; sorvete C: $34 \%$ de polpa maracujá. Médias seguidas por letras diferentes nas linhas diferem $(P<0,05)$ pelo teste SNK.

\section{DISCUSSÃo}

\section{Análises físico-químicas}

Ao compararem-se os resultados da análise físico-química do leite de cabra utilizado na pesquisa com a legislação brasileira vigente, verificou-se que o leite analisado obedece a todos os padrões de qualidade estabelecidos.

\section{Análise sensorial}

Na primeira etapa da avaliação sensorial a preferência pelo sorvete elaborado com polpa de maracujá ocorreu em virtude, provavelmente, do flavor desta fruta sob as características organolépticas consideradas ativas do leite caprino, mas também pelo fato de produtos desenvolvidos com maracujá serem 
MACEDO, L.S.O. et al. Desenvolvimento e avaliação sensorial de sorvete à base de leite de cabra com sabor de frutas tropicais. PUBVET, Londrina, V. 8, N. 21, Ed. 270, Art. 1803, Novembro, 2014.

normalmente bem aceitos. Gouvêa et al. (2010), verificando a aceitabilidade de iogurte tipo sundae de maracujá verificou que $98,1 \%$ dos provadores disseram ter gostado do produto.

A reduzida preferência do sorvete sabor cajá segundo sugestões dos provadores foi em função do baixo teor de polpa (26\%) utilizado na elaboração do produto. Clementino et al (2007) observaram aceitabilidade de 70,8\% em relação ao sabor para sobremesa aerada tipo mouse sabor cajá elaborada com leite caprino, entretanto, a proporção leite de cabra e polpa de cajá utilizada foi de 1:1 podendo-se inferir que neste caso o percentual de polpa foi efetivo para melhorar as características sensoriais desta sobremesa.

Dentre as sugestões mais freqüentes feitas pelos provadores na primeira fase da análise sensorial estava à necessidade do aumento do percentual das polpas de frutas utilizadas nos sorvetes e também acréscimo de açúcar nas formulações. De acordo com Pfaffman (1960) citado por Tomita et al. (1999) a preferência por alimentos adoçados é influenciada por uma variedade de fatores tais como os biológicos, psicológicos, sociais, ambientais, dentre outras questões como o sexo, a etnia e a sensibilidade gustativa.

Na segunda etapa da avaliação sensorial constatou-se que todos os atributos obtiveram avaliação positiva sendo classificados como "gostei ligeiramente" e "gostei moderadamente".

Em termos do atributo cor, o tratamento $C$ que continha o maior percentual de polpa de maracujá (34\%) foi o que obteve maior média de aceitação podendo-se concluir, assim, que os provadores tiveram preferência pelo produto com coloração mais acentuada.

Segundo Ribeiro e Seravalli (2007), a cor é um dos atributos mais importantes de um alimento, uma vez que determina a sua aparência e é utilizada como critério para identificação e julgamento da qualidade de um produto. A cor do sorvete de maracujá elaborado foi devida basicamente a pigmentos naturais encontrados na polpa da fruta. Segundo Silva e Mercadante (2002), os carotenóides são os pigmentos responsáveis pela coloração da polpa do maracujá, estes autores relatam ainda que alguns desses compostos possuem 
MACEDO, L.S.O. et al. Desenvolvimento e avaliação sensorial de sorvete à base de leite de cabra com sabor de frutas tropicais. PUBVET, Londrina, V. 8, N. 21, Ed. 270, Art. 1803, Novembro, 2014.

capacidade pro vitamínica A possuindo, portanto, importante papel nutricional além de atuar no combate a doenças degenerativas oculares e contribuir para a redução do risco de doenças coronarianas.

O resultado para aroma ("gostei ligeiramente" e "gostei moderadamente") obtidos para o sorvete de maracujá neste trabalho diferem dos achados de Alves et al (2009), que em análise de aceitabilidade de frozen yogurt desenvolvido com leite de cabra verificaram que o atributo aroma esteve na faixa relativa aos termos hedônicos "gostei" e "gostei muito". Estes autores frisam que o aroma de produtos elaborados com leite caprino é muito importante devido ao odor característico que este leite possui, desta forma, para futuras formulações a utilização de substâncias aromáticas pode melhorar a qualidade sensorial do produto.

A respeito do sabor do sorvete de maracujá analisado neste trabalho, de acordo com a análise de sugestões feitas pelo painel sensorial, verificou-se grande frequência de sugestões para que fossem aumentados os teores de polpa de maracujá e também de açúcar nos três tratamentos. É provável que tais sugestões tenham ocorrido em função do sabor acentuado do leite caprino. Bem como o aroma as características peculiares do leite de cabra afetam diretamente no sabor deste leite e de seus derivados. Estudos citam que o sabor do leite de cabra está relacionado ao polimorfismo genético da as 1caseína que influência não apenas no sabor deste alimento, mas também na composição e textura de seus produtos derivados. No entanto, embora a constituição e o conteúdo de certas proteínas possam desempenhar um papel importante no sabor do leite caprino, outros estudos relatam que os ácidos graxos de cadeia ramificada são responsáveis pelo sabor característico da carne do animal e do leite e seus derivados (DELACROIX-BUCHET e LAMBERET,2000; CARUNCHIA-WHETSTINE, 2005; FONSECA, 2010).

Em relação a textura do sorvete de maracujá observou-se boa aceitação, Rocha et al (2010) obtiveram $77 \%$ de aceitabilidade em relação à textura para sorvete à base de leite de cabra sabor creme. Alves et al (2009), todavia, ao 
MACEDO, L.S.O. et al. Desenvolvimento e avaliação sensorial de sorvete à base de leite de cabra com sabor de frutas tropicais. PUBVET, Londrina, V. 8, N. 21, Ed. 270, Art. 1803, Novembro, 2014.

analisarem a textura de frozen yogurt elaborado com leite caprino observaram baixa aceitação para este atributo.

A textura, nos alimentos em geral, pode ser considerada um das propriedades mais importantes, pois afeta diretamente a preferência e a aceitação por parte dos consumidores. Cientificamente a textura é um conceito puramente sensorial, cuja percepção pode se distinguir entre características: mecânicas, geométricas, de composição química, acústicas, visuais e térmicas (SILVA E JÚNIOR, 2006).

Embora bem avaliada neste trabalho, a melhora da textura foi também observada dentre as sugestões do corpo sensorial que analisou os sorvetes de maracujá. A dificuldade principal em se estabelecer uma textura adequada ao sorvete desenvolvido, deixando-o com características similares a um produto convencional foi primordialmente a artesanalidade do processo tecnológico empregado durante o seu desenvolvimento, propiciando a formação de cristais de gelo maiores e consequentemente a redução da cremosidade do produto. De acordo com Tharp (2008) dentre as principais causas da formação de cristais de gelo em sorvete estão às diferenças no ponto de congelamento deste produto acarretando diferenças na taxa de crescimento dos cristais de gelo durante as fases de choque térmico e, em função disto, causam a redução do shelf life do produto e sua aceitação pelo consumidor. Além das flutuações no ponto de congelamento, baixos níveis de sólidos totais também possuem relação com o aumento dos cristais de gelo e, consequentemente, com a textura e palatabilidade de sorvetes. Os teores totais de sólidos afetam diretamente no tamanho dos cristais de gelo, em níveis mais baixos de sólidos totais os cristais de gelo tornam-se maiores devido à maior quantidade de água presente. A probabilidade da presença de tais características diminui à medida que o total de sólidos aumenta isso ocorre porque a concentração de sólidos congelados na parte descongelada do sorvete proporciona um maior grau de imobilização da água, o que facilita o controle do crescimento destes cristais. 
MACEDO, L.S.O. et al. Desenvolvimento e avaliação sensorial de sorvete à base de leite de cabra com sabor de frutas tropicais. PUBVET, Londrina, V. 8, N. 21, Ed. 270, Art. 1803, Novembro, 2014.

Diversas substâncias podem ser utilizadas com a finalidade de otimizar a textura de sorvetes, boa parte delas de composição lipídica, protéica e glicídica, à exemplo das gorduras (lácteas e vegetais), dos sólidos desengordurados do leite, concentrados/isolados protéicos do soro e do leite, adoçantes (sacarose, dextrose e açúcar invertido, sólidos de glicose, etc), além dos emulsificantes e estabilizantes largamente empregados na indústria sorveteira. A utilização de compostos como emulsificantes e estabilizantes deve ser, no entanto, utilizada com parcimônia, pois podem causar efeito indesejável na textura de sorvetes. O excesso de substâncias emulsificantes proporciona a transformação dos glóbulos de gordura do produto em grandes blocos gordurosos, fazendo com que o sorvete pareça uma manteiga, com defeitos de corpo e derretimento lento (THARP, 2010).

Deve-se ressaltar ainda que o uso excessivo de compostos de base lipídica e glicídica em sorvetes significam aumento do conteúdo de gorduras e açúcares na dieta do consumidor e consequentemente vão em desencontro com as recomendações dos órgãos de saúde pública de todo o mundo por favorecem o surgimento ou agravo de doenças relacionadas com dietas ricas em gorduras e em açúcares que segundo Palacow e Lancha Junior (2007) podem ser atribuídas a males como a obesidade, doenças cardiovasculares, dislipidemias, diabetes mellitus tipo 2, hipertensão, osteoartrite, apnéia do sono e alguns tipos de câncer.

Em relação a intenção de compra do sorvetes de maracujá o painel sensorial disse ter dúvidas se compraria o produto. Rocha et al. (2010), observaram que $20,5 \%$ do painel sensorial ao avaliar sorvete à base de leite de cabra sabor creme disseram ter dúvidas se comprariam o produto.

A baixa aceitabilidade do leite de cabra e de seus derivados pode ser justificada pela falta de hábito da população em consumí-los devido ao difícil acesso e ao preço destes produtos quando industrializados, além das já mencionadas características ativas deste alimento.

É válido destacar também que a busca pela melhora dos atributos organolépticos do leite de cabra e de seus derivados deve envolver toda a 
MACEDO, L.S.O. et al. Desenvolvimento e avaliação sensorial de sorvete à base de leite de cabra com sabor de frutas tropicais. PUBVET, Londrina, V. 8, N. 21, Ed. 270, Art. 1803, Novembro, 2014.

cadeia produtiva. Ainda no campo, por exemplo, deve ser feita a separação de cabras e bodes, pois segundo Quadros (2008) os machos podem transmitir odores peculiares, provenientes de suas funções hormonais, para as fêmeas em lactação ou para o próprio leite devido ao fato de produzirem uma substância metabólica chamada hícrino de odor desagradável aos seres humanos.

Nas granjas leiteiras a adoção das Boas Práticas Agropecuárias e das Boas Práticas de Ordenha são indispensáveis para a obtenção do leite de cabra com qualidade sensorial, nutricional e sanitárias ideais, para tanto Chapaval et al. (2009) consideram que deve-se prezar pela saúde do úbere, conduzir um bom manejo de ordenha e fazer o controle zootécnico dos animais.

Além das boas práticas na produção leiteira de cabras, que reduzirão as características sensórias rejeitáveis desse leite pelos consumidores, soluções tecnológicas devem ser adotadas por meio de novas pesquisas com o intuito de buscar formulações mais adequadas dos sorvetes testados, mantendo-os mais próximos possíveis dos produtos convencionais.

\section{CONCLUSÃO}

O teste de ordenação-preferência realizado na primeira fase da análise sensorial mostrou que os provadores preferiram dentre os três sabores de sorvete, o sorvete à base de leite de cabra com sabor de maracujá.

Conclui-se que na segunda etapa da avaliação sensorial o sorvete à base de leite de cabra contendo a maior concentração de polpa de maracujá foi o mais bem aceito quanto o atributo cor, entretanto o teste de intenção de compra revelou que os provadores tiveram dúvidas se comprariam os produtos elaborados.

Desta forma, novas pesquisas devem ser realizadas a fim de buscar formulações que aproximem as características organolépticas dos sorvetes à base de leite de cabra dos sorvetes convencionais encontrados no mercado. 
MACEDO, L.S.O. et al. Desenvolvimento e avaliação sensorial de sorvete à base de leite de cabra com sabor de frutas tropicais. PUBVET, Londrina, V. 8, N. 21, Ed. 270, Art. 1803, Novembro, 2014.

\section{AGRADECIMENTOS}

Os autores agradecem ao Instituto Federal de Educação, Ciência e Tecnologia do Piauí pelo apoio concedido para o desenvolvimento deste trabalho. Os agradecimentos estendem-se ainda ao Centro de Ciências Agrárias (CCA) e ao Núcleo de Estudos, Pesquisas e Processamento de Alimentos (NUEPPA) da Universidade Federal do Piauí (UFPI) pela concessão de meios essenciais ao andamento desta pesquisa.

\section{REFERÊNCIA}

FREITAS, DG.F.; KHAN, AS.; SILVA, LMR. Nível tecnológico e rentabilidade de produção de mel de abelha (Apis mellifera) no Ceará. Revista de Economia e Sociologia Rural [online]. 2004; 42 (1): 171-188.

IBGE. Instituto Brasileiro de Geografia e Estatística. Produção da Pecuária Municipal. Rio de Janeiro, v. 32, $52 \quad$ p., 2009. http://www.ibge.gov.br/english/estatistica/economia/ppm/2009/ppm2009.pdf. Acesso em: 19 de junho de 2011.

MAZOCHI, V. Produção de iogurte probiótico com leite de cabra adicionado de Bifidobacterium spp. [dissertação]. Belo Horizonte: (BI): Centro Universitário de Belo Horizonte, 2002.

RIBEIRO, ELA. ; RIBEIRO, HJSS. Uso nutricional e terapêutico do leite de cabra. Semina Ciências Agrárias. 2001; 22 (2): 113-119.

ALVES, LL.; RICHARDS; NSPS.; BECKER, LV.; ANDRADE, DF.; MILANI, LI. G.; REZER, A PS.; SCIPIONI, G. C. Aceitação sensorial e caracterização de frozen yogurt de leite de cabra com adição de cultura probiótica e prebiótico. Ciência Rural. 2009; 39 (9): 2595-2600.

Associação Brasileira das Indústrias de Sorvetes (ABIS). Produção e consumo de sorvetes no Brasil. São Paulo, 2010. Disponível em: http://www.abis.com.br/estatistica producaoeconsumodesorvetesnobrasil.html. Acesso em: 19 de junho de 2011.

KHAN, S. et al. Effect of pregnancy on lactation milk value in dairy buffaloes. Asian-Aust. Journal Animal Science. 2008; 21 (4): 523-531.

INSTITUTO ADOLFO LUTZ (IAL). Normas analíticas do Instituto Adolfo Lutz: métodos químicos e físicos para análises de alimentos. São Paulo, 2008. 533p.

DUTCOSKY, S.D. Análise sensorial de alimentos. Paraná, 1996. 123p.

STATISTICAL ANALYSIS SISTEM. SAS. System for linear models. Cary: SAS Institutte, 1997. 211p.

BRASIL. Ministério da Agricultura. Instrução Normativa n.37, de 31 de outubro de 2000. Regulamento Técnico de Identidade e Qualidade de Leite de Cabra. Brasília; 2000. 8p. (Instrução Normativa n.37, 2000).

GOUVÊA, DM.; SOUZA, ÉC.; RODRIGUES, RC.; ROCHA, JCG. Iogurte tipo sundae sabor maracujá com calda de chocolate inovação e aceitabilidade. In: Congresso Nacional de Laticínios, 27., 2010, Minas Gerais. Anais...Minas Gerais: Empresa de Pesquisa Agropecuária de Minas Gerais, 2010. 5p. 
CLEMENTINO, I . M.; NASCIMENTO, J.; CORREIA, R. T. P. . Sobremesa láctea aerada tipo mousse produzida a partir de leite caprino e frutas regionais. Publica. 2007, v. 3, p. 1-8.

14. PFAFFMANN C. The pleasure of sensation. Psychological Review. 1960. p. 253-68.

TOMITA, NE; NADANOVSKY, P; VIEIRA, ALF; LOPES, ES. Taste preference for sweeteness and caries prevalence in preschool children. Revista de Saúde Pública. 1999;3(6).

RIBEIRO, EP.; SERAVALLI, EAG. Química de Alimentos. $2^{\circ}$ edição. São Paulo: Edgar Blücher, 2007.

SILVA, SR.; MERCADANTE, AZ. Composição de carotenóides de maracujá-amarelo (Passiflora edulis flavicarpa) in natura. Ciência e Tecnologia de Alimentos. 2002; 22 (3).

DELACROIX-BUCHET, A. LAMBERET, G. Sensorial properties and tipicity of goat dairy products. In: Internacional on Goats, 7., 2000, Tours. p. 559-563.

FONSECA, CR. Efeito do tempo de armazenamento do leite de cabra in natura sobre a qualidade e a estabilidade do leite de cabra em pó. [Tese]. Pirassunga: Universidade de São Paulo, 2010.

CARUNCHIA-WHETSTINE, ME. Flavor chemistry of cheese, milk powder and dried whey protein. [Dissertation]. North of Carolina (NC): University of North Carolina, 2005.

ROCHA, EMS.; DAGA, A.; FRIZON, JS.; ROMAN, JA. Análise sensorial de sorvete de creme elaborado à base de leite de cabra. In: Encontro de Divulgação Científica e Tecnológica, 5., 2010 Paraná. Anais...Paraná: UTFP, 2010. p. 98-102.

SILVA, F. A.; JUNIOR, A. M. Perfil da textura de amêndoas de noz de macadâmia (Macadamia interfoglia) secas com aplicação de energia de microondas e ar quente. Revista Ciências Exatas e Naturais. 2006, v.8 n.2.

THARP, BW. Manual técnico para o desenvolvimento de sorvetes para serem consumidos em dietas com baixo teor de carboidrato. Revista Sorvetes e Casquinhas. São Paulo: Ed. Insumos, 2008, p. 24-33.

THARP, BW. Diretrizes para formulação de sorvete lácteo. Revista Sorvetes e Casquinhas. São Paulo. Insumos, 2010, p. 32-40.

PALACOW, V.; LANCHA JUNIOR, A. H. Dietas hipergicídicas: efeitos da substituição isoenergética de gordura sobre o metabolismo de lipídeos, adiposidade corporal e atividade física e com o risco de doença cardiovascular. Arquivos Brasileiros de Endocrinologia e Metabologia, v.51 p. 389-400, 2007.

QUADRos, D. G. Leite de cabra: produção e qualidade. PUBVET - Publicações em Medicina Veterinária e Zootecnia, v. 2, p. 1, 2008.

CHAPAVAL, L.; MORORÓ, AM.; SOUSA, AP.B.; RAMOS, M.A. Boas práticas agropecuárias na ordenha de cabras leiteiras. Sobral: Embrapa Caprinos, 2009. 7 p. (Embrapa Caprinos. Comunicado Técnico 39). 